\title{
Physical Characteristics of Gelatin from Cork Fish skin in The Waters of Merauke
}

\author{
Diah Lestari Ayudiarti', Ema Hastarini, and Rini Susilowati \\ Research and Development Center for Marine and Fisheries Product Processing and Biotecnology
}

\begin{abstract}
Cork fish (Channa striata) is a swamp fish that population very abundant in Merauke. This fish meat is rich in albumin and is usually used as an additional supplement for people who have undergone surgery. Cork fish skin also contains very high protein, which one of them is gelatin. Research on physical characteristics of gelatin from cork fish skin in the waters of merauke has been done. Gelatin were made by soaked the cork fish skin into acetic acid $0.5 \mathrm{M}$ at concentration 2, 4 and $6 \%$ for 12 hours. After soaked, the skins were washed by water until neutralized ( $\mathrm{pH} 6)$, then it were extracted using aquadest $(1: 3)$ at $70^{\circ} \mathrm{C}$ for 2 hours. The filtrates then were filtered and dried in oven at temperature $40-50^{\circ} \mathrm{C}$. The result showed that the best gelatin extraction was using acetic acid $0.5 \mathrm{M}$ in concentration $6 \%$ with yield $10.15 \%$, gel strength 169.45 gbloom, viscosity $14.31 \mathrm{cPs}$, white degree 52 .
\end{abstract}

\section{Introduction}

Cork fish (Channa striata) is one of the swamp fish that has not been widely cultivated. Cork fish has physical features that have a nearly rounded body shape, and the more backward shape is compressed. Convex back, flat stomach and flat head like a snake (head snake). The body color on the back is blackish green and the abdomen is cream or white. [4] explains that cork fish fins do not have hard fingers, have long and wide dorsal and anal fins, semicircular caudal fins, wide pectoral fins with rounded ends. The proportion of body parts of cork fish includes the head and gills, meat, bones, skin, and innards. Each body part has different proportions based on the size or weight of the cork fish. The weight of the head and gills of male and female cork fish increases with increasing fish weight. The skin is part of the body of cork fish whose utilization is still very limited, namely as a skin cracker. Cork fish skin has a fairly high protein content, where this protein can be extracted to get gelatin.

Gelatin is a soluble polypeptide derived from collagen, which is the main constituent of skin, bones, and connective tissue of animals. Gelatin is obtained through partial hydrolysis of collagen. When collagen is treated with acid or base and followed by heat, the fibrous structure of collagen is broken irreversibly to produce gelatin [20]. The conversion rate of collagen to gelatin is related to the level of damage from the pre-treatment and extraction processes, $\mathrm{pH}$, temperature and time of extraction [10]. Gelatin is one of the most widely used ingredients in the pharmaceutical and food industries. Mammalian skin and bones are used as raw materials for the gelatin industry. However, the presence of bovine spongiform encephalopathy (BSE) disease, transmissible spongiform encephalopathy (TSE) and foot and mouth disease (PMK) has caused

\footnotetext{
${ }^{*}$ Corresponding author : diah_stari@yahoo.co.id
} 
anxiety among users of gelatin and gelatin products derived from these mammals [11]. Muslims and Jews are prohibited from using ingredients from pigs and Hindus forbidden to use ingredients from cows [13].

The effect of extraction conditions on gelatin has been reported for megrim [15], tilapia [8], yellowfin tuna [3], alaska pollock [20], horse mackerel [2] and skate [3]. However, fish gelatin from cold waters is not as good as mammalian gelatin. Fish gelatin can be the same as the quality of mammalian gelatin depending on the species and processing conditions. [19]. It has been reported that gelatin from fish species that live in warm water habitats such as tilapia [8] and carp [13] have thermostability and rheological properties better than gelatin obtained from cold-water species fish such as cod, salmon or pollack alaska. In addition to the basic physicochemical properties, such as parameters of composition, solubility, transparency, color, smell and taste, the main attributes that determine the overall best quality of commercial gelatin are gel strength and thermal stability (gelling and melting by temperature) [6]. Thermal stability, relative molecular mass and microstructures are sufficient physical properties for quality biodegradable materials in food wrapping and packaging applications. The purpose of this study was to obtain gelatin from the skin of cork fish waste by products.

\section{Materials and methods}

\subsection{Materials}

The gelatin raw material was used cork fish skin. Cork fish skin was obtained from the byproducts of fillets. Cork fish from merauke was caught alive with size approximately one kilogram for each fish. The fish was filleted then the meat was used for albumin extraction and the skin was used for gelatin extraction material. Before extracting, fish skin was cleaned first from dirt and blood. Other material used to extract gelatin were acetic acid and aquadest.

\subsection{Methods}

Gelatin were made by soaked the cork fish skin into acetic acid $0.5 \mathrm{M}$ at concentration 2,4 and $6 \%$ for 12 hours. After 12 hours, the skin became swelling, then it were washed by water until neutralized (to $\mathrm{pH}$ 6). The swelling skin then extracted using aquadest (1:3) at $70^{\circ} \mathrm{C}$ for 2 hours. The filtrates then were filtered and were dried in oven at temperature $40-50^{\circ} \mathrm{C}$. Gelatin sheets then were blended and analyzed for their physical characteristics including gel strength, viscosity and whiteness.

\section{Results and discussion}

Gelatin from cork fish skin has a bright yellow description and has not smell fishy. The results showed that the value of gelatin yield obtained ranged from $8.18-10.15 \%$, the gelatin gel strength value ranged from 148.8-169.45 gbloom, the gelatin viscosity ranged from 10.56$14.31 \mathrm{cPs}$ and whiteness ranged from 52-58. 


\subsection{Yield}

The yield is one of the important parameters in making gelatin. The yield was calculated based on the comparison between the gelatin powders produced with the weight of the fish skin used. The values of the gelatin yield ranged 8.18 until $10.15 \%$ and it can be seen in Figure 1 .

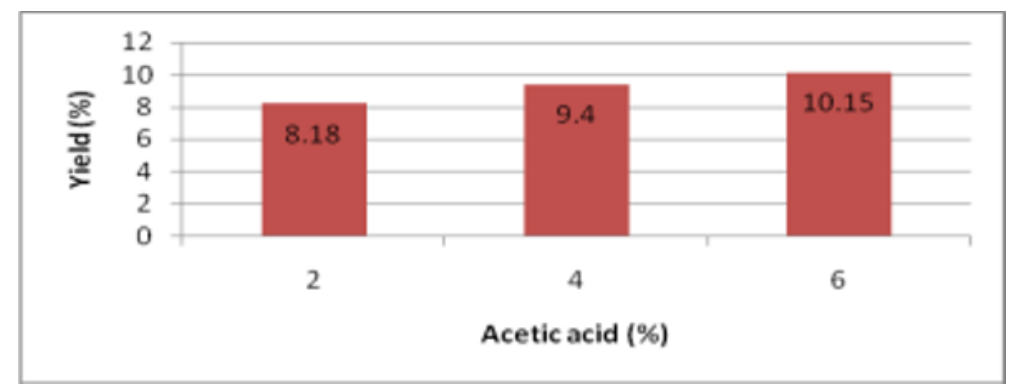

Fig. 1. Graphic of fish gelatin yield

The highest yield is owned by extraction using 6\% acetic acid. [14] was mentioned, the best yield extracted dry skin of Spanish mackerel using acetic acid was 13,03\%. Acid solvents cause the structure of collagen proteins in fish skins expand and open [7]. The extraction process using heat will further cuts hydrogen and covalent bonds and destabilizes triple helix through a helixto-coil transition, converting it become gelatin [1]. There is a tendency that more high concentration of acetic acid, the yield the result will be even higher. Because more protein is denatured by acetic acid. The acidic pretreatments was effective on removing non-collagenous proteins by destroying certain cross linkage chemicals and breakage of peptide bonds. This process was causing a large amount of swelling in fish skin, and resulting highest gelatin yield and gel strength [1].

\subsection{Gel strength}

Gelatin gel strength is defined as the amount of force required by the probe to press the gel as high as four mm until the gel breaks. The unit to show the strength of the gel produced from a certain concentration is called the degree of bloom. The value of gel strength ranges from 148.80 gbloom to 169.45 gbloom. The highest gel strength is possessed by extraction using $6 \%$ acetic acid. The gel strength result of the fish gelatin can be seen in Figure 2. 


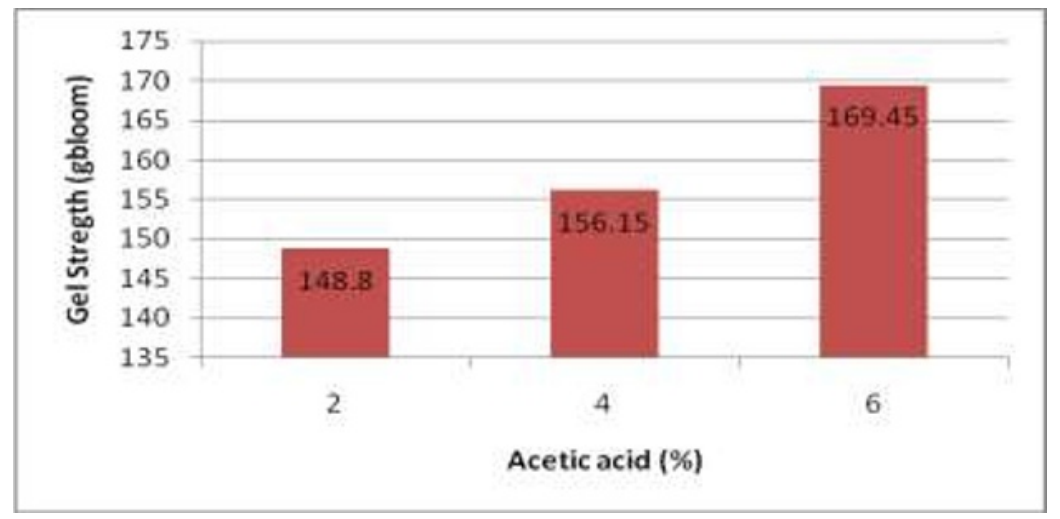

Fig. 2. Graphic of fish gelatin gel strength

Gel strength is very important in determining the best treatment in the gelatin extraction process because one of the important properties of gelatin is being able to convert liquids into solids or convert soles into reversible gels. This ability causes gelatin to be very widely used, both in the fields of food, pharmacy, and other fields. The strength value of gel from cork fish skin is $169.45 \mathrm{~g}$ bloom, this value still meets the gelatin gel strength standard required by Tourtellote, namely 75-300 bloom. Trilaksani et al. [18] mentioned that 3\% of acetic acid was the best concentration in extracting snapper skin.

During the extraction process occurs development of gelatin molecules, heat will open bonds to the gelatin molecule and liquid that was originally free flowing into a thick solution. Soaking fish skin in a solution of acetic acid with higher and longer concentration soaking time is longer will cause a chain cut amino acids get higher and higher causing further hydrolysis in collagen which has been dispersed into gelatin to produce acid chains shorter amino [7]. Higher concentration of acetic acid results in gel strength value, the resulting gelatin is getting higher up acetic acid concentration and soaking time [18].

\subsection{Viscosity}

Gelatin viscosity is influenced by gelatin $\mathrm{pH}$, temperature, gelatin concentration and the addition of other electrolytes in gelatin solution, the lower the temperature of the gelatin solution (maximum $40^{\circ} \mathrm{C}$ ) and the higher the concentration of gelatin the higher the viscosity [17]. The value of viscosity ranges from $10.56 \mathrm{cPs}$ to $14.31 \mathrm{cPs}$. The highest viscosity is possessed by extraction using $6 \%$ acetic acid. The viscosity result of the fish gelatin can be seen in Figure 3. 


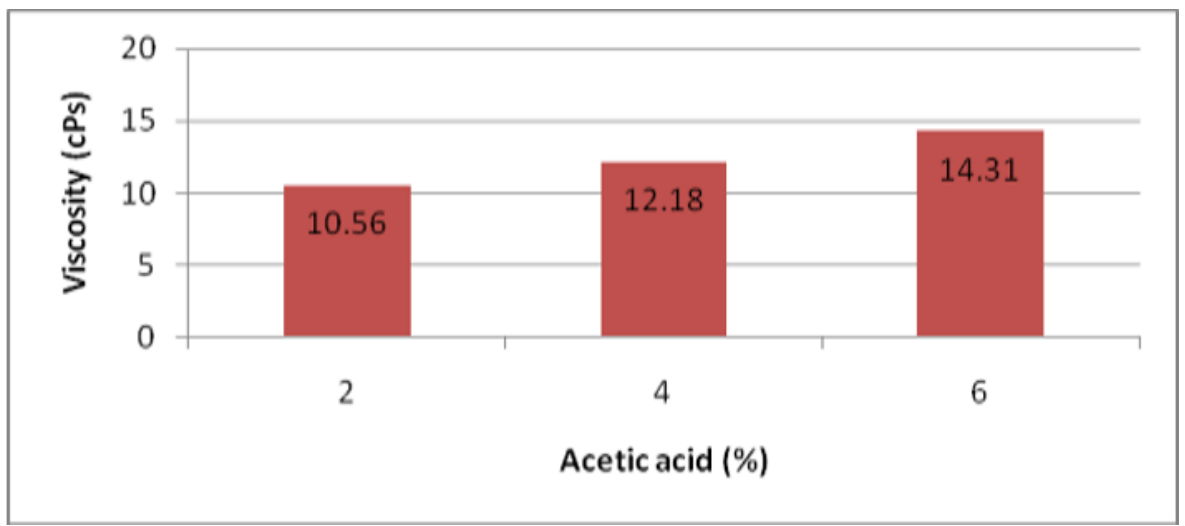

Fig. 3. Graphic of fish gelatin viscosity

The viscosity value of this gelatin will affect the final product of a product [9]. The viscosity of gelatin from cork fish skin tends to be higher compared to gelatin from fish bones. Therefore, gelatin for cork fish skin is suitable for use in the pharmaceutical industry and film formation which requires high viscosity [5]. The high value of this viscosity caused by the breakdown of collagen into gelatin occurs optimally so that the amino chains formed are quite long and the viscosity becomes high [12]. Gelatin viscosity is influenced by molecular weight with the lowest viscosity value of gelatin ranging from 6-8 $\mathrm{cP}$ [8]. The gelatin viscosity value of cork fish skin is $17.4 \mathrm{cP}$, this value meets the food standard gelatin of [16] which is more than $2.5 \mathrm{cP}$.

\subsection{Whiteness}

The white degree is a picture general color of gelatin. In general the white degree of gelatin is expected to approach $100 \%$, because of the high quality gelatin usually colorless, so the application wider. The degree of white gelatin will affect the application of a product. Whiteness values ranged from 52 to 58 . The highest white degree was possessed by extraction using $2 \%$ acetic acid. The whiteness result of the fish gelatin can be seen in Figure 4.

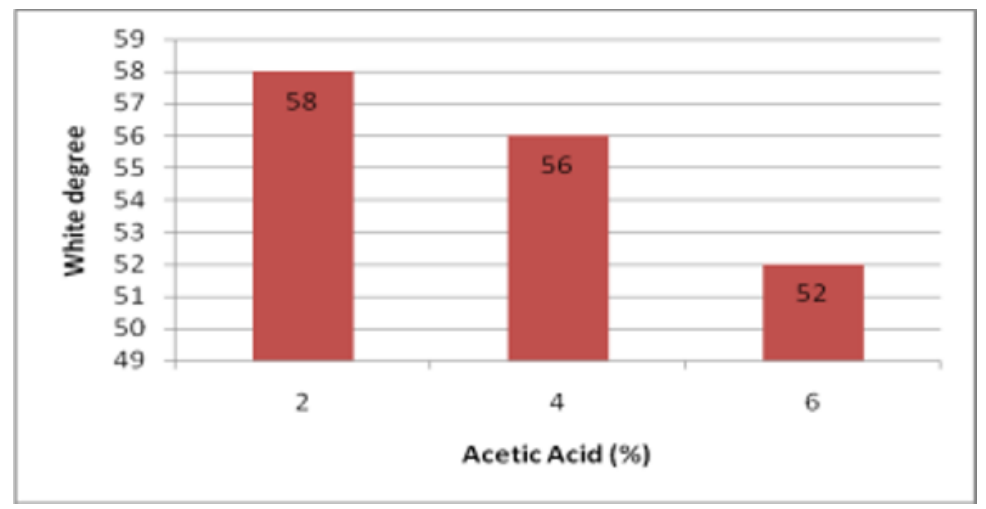

Fig. 3. Graphic of fish gelatin white degree

Low value of white degree on gelatin of cork fish skin is suspected because during heating when extraction occurs non-enzymatic browning or reaction process maillard between amino 
groups in amino acids and the results of fat oxidation are still sufficient high which causes pigment chocolate or melanoidin. Drying technique also affects the value of white degrees.

\section{Conclusion}

The result showed that the best gelatin extraction was using acetic acid $0.5 \mathrm{M}$ in concentration $6 \%$ with yield $10.15 \%$, gel strength 169.45 gbloom, viscosity $14.31 \mathrm{cps}$, white degree 52 .

\section{References}

1. Ardekani VS, Mahmoodani F, See SF, Yusop SM and Babji AS. Sains Malaysiana 42 (12): 1697-1705 (2013).

2. Badii, F and Howell, N.K. Food Hydrocolloids 20: 630-640 (2005).

3. Cho, S.M.; Gu, Y.S.; Kim, S.B. Food Hydrocoll. 19: 221-229 (2005).

4. Djuhanda T. 1981. World of Fish. Bandung: Armico. 191 p.

5. Fahrul. 2005. [Thesis]. Bogor: School Postgraduate. Bogor Agricultural Institute.

6. Gomez Guillen MC and Montero P Journal of Food Science 66 (2) 213 -16. (2001).

7. Gunawan F, Suptijah P, and Uju. JPHPI 20 (3):568-581 (2017).

8. Jamilah, B. and Harvinder, K. G. Journal of Food Chemistry 77: 81-84 (2002).

9. Johns P. 1977. The Structure of Competition of Collagen Containing Tissue. Di dalam Ward AG and Courts A. editor. The Science and Technology of Gelatin (New York: Academic Press, 1977)

10. Johnston-Banks, F. A. Gelatin. In Harris, P. (Ed.), Food Gels. (London: Elsevier Applied Food Science Series, 150 pp, 1990)

11. Jongjareonrak A, Benjakul S, Visessanguan W, Nagai T, Tanaka M. Food Chem 93 (3):475-484 (2005).

12. Lehninger, A. L. Biochemical Basics. Volume I (Revised Edition) (Erlangga, Jakarta, 1997).

13. Kasankala, LM. Xue, Y. Weilong, Y. Hong, S. D. He, Q. Bioresource Technology 98: 3338-3343 (2007).

14. Kusumaningrum1 I, Pranoto Y and Hadiwiyoto S. 2018. Extraction optimization and characterization of gelatine from fish dry skin of Spanish mackerel (Scomberromorus commersoni). 1st International Conference on Tropical Studies and Its Application (ICTROPS). p. 1-8

15. Montero, P. and Gomez-Guillen, M.C. Journal of Food Science 65: 536-537 (2000).

16. Norland, R. E. Fish Gelatin. In: Voigt, M. J., Botta, J. R. (Eds.), Advances in Fisheries Technology and Biotechnology for Increased Profitability (Technomic Publisher Co. Inc., Lancaster, 297 pp, 1990).

17. Stainsby, G. The Physical Chemistry of Gelatin in Solution. In A.G. Ward and A. Courts (Ed.) The Science and Technology of Gelatin (Academic Press, New York, 1977).

18. Trilaksani W., Nurilmala M. and Setiawati I. H. JPHPI 15 (3):240-251 (2012).

19. Yang H, Wang Y, Jiang M, Oh J, Herring J, Zhou P. J Food Sci. 72(4):C188-C195 (2007)

20. Zhou P. and Regenstein J. M. Journal of Food Science 70: C392-C396 (2005). 